\title{
The Perception of "Training Availability" Among Certified Nurse Aides: Relationship to CNA Performance, Turnover, Attitudes, Burnout, and Empowerment ${ }^{1}$
}

\author{
Dale E. Yeatts, Ph.D. \\ Cynthia Cready, Ph.D. \\ James Swan, Ph.D. \\ Yuying Shen, M.A.
}

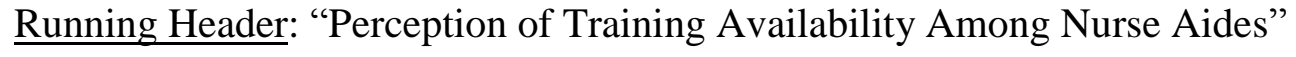

\footnotetext{
${ }^{1}$ Authors Note: Dale E. Yeatts, Ph.D., Professor, Department of Sociology, University of North Texas, Denton, Texas, Yeatts@unt.edu; Cynthia Cready, Ph.D., Associate Professor, Department of Sociology, University of North Texas, Denton, Texas, Cready@unt.edu.; James Swan, Ph.D., Professor, Department of Sociology, University of North Texas, Denton, Texas, Swan@ unt.edu , Yuying Shen, M.A., Ph.D. candidate, Department of Sociology, University of North Texas, Denton, Texas, YuyingShen@my.unt.edu.

Acknowledgments: This research was supported by The Commonwealth Fund, a private, independent foundation based in New York City. The views presented here are those of the authors and not necessarily those of The Commonwealth Fund, its directors, officers, or staff. We thank C.C. Young; Christian Care Centers, Inc.; Evangelical Lutheran Good Samaritan Society; Mariner Health Care; Nexion Health, Inc.; and Pacific Retirement Services Inc. for participating with us in this adventure.
} 


\title{
The Perception of "Training Availability" Among Certified Nurse Aides: Relationship to CNA Performance, Turnover, Attitudes, Burnout, and Empowerment
}

\begin{abstract}
The purpose of this study was to examine the relationship between the certified nurse aides' (CNAs') perception that "training is always available when needed" and the CNAs' performance, turnover, attitudes, burnout, and empowerment. The data come from a larger study where a self-administered survey instrument was completed by 359 CNAs working in 11 nursing homes (NHs) in the north Texas region. The data analyses largely support previous research. "Perceived training availability" was most highly associated with participation in decisionmaking, information exchange, the procedures used, and satisfaction/commitment. The data suggest that the CNAs surveyed may not have received substantial training related to the depersonalization of residents, self-esteem, and direct decision-making. Further, the findings suggest an opportunity to improve training by including a component to help CNAs transfer the skills and knowledge learned during the training to the actual provision of resident care.
\end{abstract}

Key Words: Nursing homes, certified nurse aides, training, performance, job attitudes. 


\section{The Perception of "Training Availability" Among Certified Nurse Aides: Relationship to CNA Performance, Turnover, Attitudes, Burnout, and Empowerment}

It wasn't until the mid to late 1980s that professionals of long-term care began to recognize a paramount need for the training of those who provide direct care to nursing home residents (Burgio \& Burgio, 1990; Aylward, Stolee, Keat \& Johncox, 2003). This recognition came as a result of a paradigm shift in thinking from a custodial model of care to a therapeutic or medical model that emphasized restorative or rehabilitative care. New learning and development was required to implement this new model of care (Fitzgarald, Ecclestone, Jones, Orange, Stolee \& Lazowski, 2001). Knowledge requirements were outlined in the Omnibus Reconciliation Act of 1987 which included new regulations for resident care, a reduction and elimination of physical and chemical restraints and the development of individual care plans to ensure optimal functioning. Today, training requirements are again being re-thought as nursing home managers shift their paradigm in thinking to one of "personalized" resident care. This comes in addition to, rather than the replacement of, a focus on the medical conditions of nursing home residents (Menne, Ejaz, Noelker, \& Jones, 2007; Stott, Brannon, Vasey, Kansky \& Kemper, 2007).

An examination of literature reviewing training in nursing homes (NHs) finds that many

journal articles focus on what should be provided with less attention given to the actual effects of the training (Wunderlich \& Kohler, 2001). There are a variety of reasons for this including the cost and time involved in a well-designed evalution. Aylward, et al. (2003, p.260) have noted "In recent years, many educational programs have been undertaken or initiated in long-term care facilities. The effectiveness of this training and its long-term impact on resident care are unclear, as most initiatives do not include an evaluation component or are not formally evaluated over 
time.” Earlier, similar conclusions were reached by Burgio and Burgio (1990), Beck, Ortigara, Mercer and Shue (1999) and Johncox (2000).

When considering the actual effects of training in NHs, research suggests that there is typically a struggle in transferring knowledge into practice as certified nurse aides (CNAs) have difficulty when trying to implement what has been taught. Broad (1997) has suggested that only $10-30 \%$ of training activity is actually transferred into practice. Aylward, et al. (2003) in their review of 48 training evaluation studies have concluded that there is minimal evidence that knowledge gained from training programs is sustained over time. They find that part of the problem is the lack of follow-up evaluations that could document positive effects. But, they also note that organizational and system factors may be accounting for some of the difficulty in transferring knowledge to practice.

The purpose of this study was to examine the relationship between the CNAs' perception that "training is always available when needed" and the CNAs' performance, turnover, attitudes, burnout, and empowerment. While our data do not allow us to evaluate a specific training program or to establish "cause and effect," we are able to examine whether the perception of having training available is related to CNA job attitudes (e.g., job satisfaction, commitment, selfesteem, stress), burnout, empowerment, turnover, and performance. There are many studies that have suggested that, when training is amply provided, attitudes improve, turnover reduces, and performance increases. If these studies are correct, then we would expect those CNAs, who perceive training to be "always available," to be more likely to report these desirable outcomes. Studies reporting the effects of training are reviewed below. 


\section{Effects of Training on CNA Attitudes}

Research has found training to be associated with a variety of job attitudes including satisfaction, commitment, self-esteem, feelings of being treated fairly, burnout, and empowerment. When considering job satisfaction, Braun, Suzuki, Cusick and Howard-Carhart (1997) have described the effects of training materials they developed to reduce NH resident abuse and neglect, including a 12-minute video drama and a 12-page booklet. They discovered that a side effect of the training was an increase in job satisfaction. Banaszak-Holl and Hines (1996) in their study of staff turnover also found that job training increased CNA satisfaction. They attributed the training's effect to its providing the CNAs with additional control over their work and to its affect on their perception that their employers were willing to invest in their future. Owens (2006) examined the effects of training on 218 employees from a local state subdivision in the southeastern United States. His analysis found a positive relationship between the amount of training provided and job satisfaction. Additional studies reporting the positive effects of training on job satisfaction include Menne, et al. (2007), Ejaz, Noelker, Menne and Bagakas (2008), Stott et al. (2007), and Coogle, Parham, Jablonski and Rachel (2007).

Much less research was found to examine the relationship between training and organizational commitment, where organizational commitment refers to affection for, belonging to, or dedication/attachment to the organization. Owens (2006), in his study of 218 state employees who did or did not receive training concluded that the provision of training increased the employees' commitment to their organization. Coogle, et al. (2007) have described a variety of training techniques used to enhance employee problem-solving, communication, and stress management. In their evaluation of these training techniques they discovered that training positively affected an employee's organizational commitment. Similarly, Stott, et al. (2007) 
have discussed the positive effects that training has on employee job attitudes including commitment. Other studies noting positive effects include those of Menne, et al. (2007) and Schur, Noelker, Looman, Whitlatch and Ejaz (1998).

"Burnout" among CNAs has been defined as emotional exhaustion or the depletion or draining of emotional resources in doing one's work. More recently, its definition has been expanded to include two additional dimensions: depersonalization or cynicism about one's work in order to distance oneself from the work (Leiter \& Schaufeli, 1996), and low professional efficacy or a feeling that one's accomplishments and competence are low (Maslach, Jackson \& Leiter, 1996). A very similar concept, "stress," has been defined in terms of personal and work conditions (e.g., ability to pay bills, constant shift changes) that create worries (Ejaz, et al., 2008). Hatinen, Kinnunen, Pekkonen and Aro (2004) have reported on the results of a training program designed to reduce burnout. They concluded that training can reduce burnout but must be targeted to specific dimensions of burnout. Similarly, Chappell and Novak (1992, p.351) studied the effects of social and organizational supports on stress and burnout. They concluded that "...training to work with residents with cognitive impairment...can assist nursing assistants in dealing with burnout and perceived job pressure." And Menne, et al., (2007) have concluded that properly focused training is likely to improve problem solving among CNAs and reduce job stress. Other studies reporting positive effects of training on stress and/or burnout include Coogle, et al. (2007) and Hoeffer, et al. (2006).

Other job attitudes found to be affected by training include feelings of empowerment, self-esteem, and feelings of being treated fairly. Coogle, et al. (2007) have reported on the positive effects that "enhancement" training (Enhanced Care Assistant Training-ECAT) can have on empowerment and self-esteem. Yeatts and Cready (2007) have described training specifically 
designed to increase CNA empowerment through the use of empowered work teams. Similarly, Banaszak-Holl and Hines (1996) have concluded that training can allow employees to feel more control over their work (see also Yeatts and Hyten, 1998). And, Hoeffer, et al. (2006) drew similar conclusions about training and empowerment from their study of two training programs designed to improve bathing practices of residents. Finally, when considering "fairness", Owens' (2006) analysis of 218 employees from state local subdivisions showed that training can result in employees feeling a sense of "interactional justice," that is, the feeling of being treated fairly by one's supervisor.

\section{Effects of Training on CNA Turnover, Absenteeism and length of Employment}

There are numerous studies that have concluded that training can result in reduced turnover. For example, Morgan and Konrad (2008) have presented data analyses indicating that specialized training for CNAs in North Carolina improved retention rates. Nakhnikian, Wilner, and Hurd (2002, p.44) have concluded that "providing CNAs with adequate preparation and support through improved training is key to improving retention.” Grant, Kane, Potthoff and Ryden (1996), in their study of specialized dementia training in 124 nursing facilities, concluded that training appeared to affect the retention of CNAs but were hesitant to make firm conclusions since their data were cross-sectional. Other studies reporting a positive effect of training on turnover include Owens (2006), Harris-Kojetin, Lipson, Fielding, Keifer and Stone (2004), Legg (2007), and Menne, et al. (2007). Interestingly, one study found no effects of training on turnover. Banaszak-Holl and Hines (1996) examined data from 250 nursing homes from 10 states and combined these data with the county characteristics for each nursing home. While they uncovered a number of factors affecting turnover, such as "CNA involvement in care 
planning," no effects were found for the provision of training, measured as "the number of hours of CNA training provided."

Much less research was found that focused on the effects of training on absenteeism and length of employment. Coogle, et al. (2007) have concluded from their study of specialized training in nursing homes that decreased absenteeism is likely a result. Maas, Buckwalter, Swanson and Mobily (1994) and Wunderlich and Kohler (2001) have reached similar conclusions.

\section{Effects of Training on CNA Performance}

Most of the evaluation studies found, that focused on CNA training, examined the direct effects of training on some aspect of a CNA's performance. And, in most cases, training was found to have desirable effects. For example, Majumdar, Browne, Roberts and Carpio (2004) randomly assigned 114 nurses and homecare workers to experimental (training) and control groups. After one year, they found that patients who received care from trained providers showed more improvement in functional capacity. Burgio, et al. (2000) reported on the effects of "communication skills training" provided to CNAs. They found that residents who received care from trained CNAs received more communications from them, resulting in better care, than did residents in a control group. Hoeffer, et al. (2006) examined the effects of "person-centered training" related to giving showers and towel bathes. They found that the training improved CNA caregiving behaviors. Other studies citing the positive effects of training on performance include Legg (2007), Coogle, et al. (2007), and Stott, et al. (2007). 


\section{Methods}

As noted above, the purpose of this study was not to evaluate a specific training program but, instead, to examine the relationship between a CNA's belief that "training is always available when needed" and the outcomes discussed. Provided below is first a description of the data collection procedures and the CNA participants. This is followed by a description of the questionnaire items, concepts, indices created, and the data analysis techniques used.

\section{Data Collection and CNA Characteristics}

The data come from a larger study where a self-administered survey instrument was completed by 359 CNAs working in 11 NHs in the north Texas region. Questionnaires were distributed to and collected from CNAs at their NHs by the researchers. The 11 NHs were surveyed between 2002 and 2005. NHs were selected to allow for variation in size, private vs non-profit, location (urban, suburban, rural) and income level. The response rate was $88 \%$. A complete description of the data collection procedures is provided by Yeatts and Cready (2007).

The CNAs can be characterized as non-White females, not married, in their 30's and having some difficulty paying bills (Table 1). More specifically, 88 percent of the CNAs were women, 53 percent were not married, $58 \%$ were non-White, the average amount of schooling was 11.8 years, average age was 37 years, and $76 \%$ reported difficulty paying bills sometimes, usually, or always.

Questionnaire Items, Concepts, and Indices

The CNAs responded to a series of statements by using a 5-point Likert-type scale ranging from 1 for "strongly disagree" to 5 for "strongly agree." Many of these items were 
drawn from existing instruments that measure the concepts of interest. These include those developed by Cook, Hepworth, Wall, and Warr (1979); Hackman and Oldham (1980); Maslach, Jackson, and Leiter, (1996); McGee and Ford (1987); Quinn and Staines (1979); Spreitzer (1995); and Yeatts and Hyten (1998). When necessary, statements were modified to reflect the uniqueness of the nursing home environment. For example, the word "recipient" was replaced by the word "resident" in burnout items such as "I feel I treat some residents as impersonal objects" (Maslach et al, 1996). When items could not be found in previous studies, items were developed and pretested prior to the survey.

For most concepts of interest, the questionnaire items were used to create indices to represent them. All the indices created consist of at least three questions. Exploratory and confirmatory factor analyses were used to identify and confirm the ability of the items to reflect a particular concept. The standardized Cronbach's alphas for the indices ranged from .50 to .84 with the majority above .70 (Appendix A). The lowest found (.50) was for the index "Care of Residents". Three items were used to measure the CNAs' ability to check on residents with regard to whether the resident (1) has eaten all that she/he wants, (2) has been turned in bed when needed, and (3) has been asked if she/he needs anything. The three items were treated as a single index because each focuses on the CNAs' ability to satisfactorily do her work. It is reasonable to suspect that the low Cronbach's alpha was found because the three items represent three different tasks that may involve competing modes of relating to residents. Neverthless, it was felt that including the index, even though it has a low alpha, would be more informative than not including it at all.

Once the items for an index were determined, the individual scores on each item were added together and divided by the number of items added together. This calculation allowed the 
index score to remain in the original range of the individual items (i.e., 1 to 5 or strongly disagree to strongly agree). Appendix A provides each concept, the number of items used to measure it, the standardized Cronbach's alpha for the index, and one of the items used in the index. The item provided in the Appendix is the one most highly correlated with the index (all statements for each concept are available upon request).

Concepts measured included: CNA performance, measured as care of residents, procedures used, and information exchange; CNA turnover measured as intent to quit and length of employment; CNA attitudes measured as satisfaction/commitment, self esteem, and treated fairly; burnout measured as exhaustion, depersonalization, and efficacy; empowerment measured as direct decision-making and participation in decision-making; and the availability of training as perceived by CNAs. Originally, the questionnaire was designed to measure job satisfaction and commitment separately. However, a factor analysis and standardized alphas showed that the items used to measure these concepts actually measured a single concept. Therefore, we created a single index (referred to as "satisfaction/commitment"). "Available Training" was measured by adding together three items and then dividing the sum by 3 (i.e., the number of items added together). Two of the three items were identical but located in different parts of the questionnaire. The duplicate items stated: "Training is available whenever I need it." The third item stated: "Whenever I need additional training, I can get it." CNA scores on these three items, once added together and divided, were recoded into one of three groups: Strongly Disagree/Disagree, Neutral, and Agree/Strongly Agree. As is discussed in the data analysis section, these groups were then compared with regard to the indices created (e.g., performance and job attitudes measures). 


\section{Data Analysis}

A variety of checks were performed on the data for outliers. Given the length of the questionnaire (113 items), there was some concern that some CNAs may not have read all statements carefully. To test for this problem, three pairs of statements were included in the questionnaire with each statement in a pair identical or with one of the two worded in the opposite direction (positive statement vs negative statement). If the respondent was not consistent in his or her responses on at least two of the three pairs of questions, the case was removed from the analysis. As a result, nine cases were removed ( 2.5 percent of all cases). In addition, box plots were examined for univariate outliers and Mahalanobis distance measures were examined for multivariate outliers. Nine cases were subsequently identified as outliers. However, after running the data analyses (MANCOVAs and ANCOVAs) with and without these cases, it was found that the results were almost identical with no substantive differences. Therefore, the cases were not removed.

A multiple analysis of covariance (MANCOVA, also referred to as two way factorial analysis of variance) was performed for each group of dependent variables to help identify the relationship between "perceived training availability" and the outcome measures. The MANCOVAs were also used to assist with an examination of potential Type 1 error (rejecting the null hypothesis of no difference when it is in fact true). An analysis of variance (ANCOVA) was used to examine more closely the relationship between "perceived training availability" and each outcome measure. In performing the MANCOVAs and ANCOVAs, all appropriate diagnostics were examined and all assumptions met. Dummy variables for the nursing homes were included in each MANCOVA, as well as in each ANCOVA, to control for differences between nursing homes. Wilk's Lambda was used to determine MANCOVA significance for 
equal covariance matrices across groups and Pillai’s Trace was used to determine significance for unequal covariance matrices. The Bonferroni calculation to adjust for Type 1 error was used in determining significance.

\section{Findings}

An examination of MANCOVAs shows that all five groups of dependent variables were related to a CNA's perceived availability of training (referred to as perceived training) with the size of the partial eta squares relatively small (Table 2). Perceived training was most highly related to CNA performance and empowerment, explaining nine percent of the variance of each, after controlling for the differences between nursing homes. Training was less related to CNA attitudes and burnout, with six and five percent of the variation explained, respectively, after controlling for nursing homes. Finally, only three percent of the variation in turnover was explained by perceived training, after controlling for nursing homes.

An examination of ANCOVAs shows that the participation in decision-making and information exchange were most highly related to perceived training with 16 and 15 percent of the variation explained, respectively. The next largest partial eta squares were found for procedures used, satisfaction/commitment, and exhaustion $(9,9$, and 7 percent of variation explained respectively). The only variables not related to perceived training were "length of employment" and "direct decision-making".

An examination of the means, comparing the three groups of CNAs, shows that the largest group differences were found with respect to participation in decision-making and information exchange. Those who disagreed/disagreed strongly that "training is available when needed" scored relatively low on these two variables ( 2.4 and 2.9 respectively), i.e., they perceived 
participation in decision-making and information exchange to be very low. On the other hand, those who agreed/agreed strongly that "training is available when needed" scored much higher on these dependent variables (3.1 and 3.6 respectively). Dependent variables showing relatively moderate effects included: intent to quit, satisfaction/commitment, and treated fairly, with a .5 difference in means between those who disagreed/disagreed strongly and those who agreed/agreed strongly that perceived training was available when needed. Dependent variables with very little or no difference between these two group included length of employment and direct decision-making.

\section{Discussion}

There are several shortcomings/limitations of the analysis to be considered. It is highly likely that a CNA's "perceived" availability of training does not reflect exactly the amount of training that was actually available to the CNA or the amount of training the CNAs actually received. Unfortunately, exact amounts of training available to each CNA is not known. One factor that could prejudice the CNA's perception is the CNA's attitude toward the NH. Those who had a positive attitude toward the $\mathrm{NH}$ might have perceived training availability more positively than those who had a negative attitude toward the NH. Interestingly, the partial eta squared for CNA attitudes (.06) and for satisfaction/commitment more specifically (.09) were not among the largest found (Table 2). If the CNAs' perception of training was simply a reflection of their satisfaction with the NH, one would expect the partial eta squares to be much larger. It is also important to note that the NHs and CNAs were not randomly selected and all come from the north Texas region. Therefore, generalizing the findings to CNAs nationally is problematic. 
Given these shortcomings of the data, it is reasonable to expect that "perceived" training availability does reflect, at least to some extent, the "actual" availability of training. With this in mind, the largest eta squares were found for CNA performance and empowerment. There is no doubt that one of the primary purposes of CNA training is to enable the CNAs to perform their tasks at a higher level. The findings indicate that those CNAs who perceived "training available when needed" were more likely to report effective procedures for caring for residents, were more likely to report receiving regular updated information, and were more likely to have time to care for residents. CNA procedures, that might have benefited from training, range from how to get residents into the cafeteria in a timely fashion to how to ensure that all residents are hydrated. Regular updated information is important to a CNA's performance. This can range from the newest discoveries related to resident care to more subtle types of information such as the personal preferences of specific residents. The "care of residents" was measured in terms of the CNAs ability to perform her duties with regard to turning residents in their beds, making sure residents ate all their food, and asking residents if they needed anything. Interestingly, this performance measure had the smallest relationship to perceived training of the three (eta squared $=.03 \mathrm{vs} .09$ and .15$)$ This suggests that other factors were more important to these CNA responsibilities than training. For example, it is reasonable to suspect that the ratio of staff to residents had a large effect on the CNAs ability to find time to turn residents in their beds, make sure residents have eaten their food, and ask residents if they needed anything.

When considering the relatively large relationship between empowerment and perceived training (MANCOVA eta squared $=.09$ ), it is interesting to note that "participation" in decisionmaking had a much stronger relationship to training (ANCOVA eta squared $=.16$ ) than did "direct" decision-making (ANCOVA showed no significant relationship). Participation in 
decision-making refers to a partnership between the CNAs and nurses where nurses rely on the suggestions and recommendations of the CNAs. Direct decision-making refers to working conditions where the CNA is left to make her own decisions about the work. This can include determining who will do what each day, the order in which to do things, and/or the procedures used. At first glance, it is surprising that those CNAs who perceived training to be always available had no more direct-decision making responsibility than those who did not perceive training to be always available. After all, wouldn't the NH management be particularly concerned about CNA training for those who are given the responsibility of making decisions on their own. While we can only surmise what might be the cause of this lack of relationship, it is reasonable to suspect that the CNAs with direct decision-making need more extensive training than a typical CNA. And, while NH managers may not fully recognize the need for additional training, the CNAs, who must carry out these decision-making responsibilities, do. Consequently, some of these CNAs may have perceived a need for more training than what was being made available and subsequently "off-set" any positive association between available training and direct decision-making. On the other hand, those CNAs who were only providing suggestions and recommendations, when it came to decision-making, needed less training and so were more likely to perceive training to be available when needed.

The relationships between perceived training and CNA attitudes and burnout were noticeably smaller with partial eta squares (MANCOVAs) of .06 and .05 respectively. Both of these concepts appear to be more related to CNA feelings and perceptions of their job than to the performance of the work itself. With regard to attitudes, CNAs who perceived the training to always be available when needed were also more satisfied/committed to the $\mathrm{NH}-$ that is, they were more likely to agree or strongly agree with the statement "I feel emotionally attached to this 
NH" and to the statement "Generally speaking I am very satisfied with my job" (ANCOVA eta squared $=.09$ ). Unfortunately, the data do not allow for a distinction to be made between the two concepts of organizational commitment and job satisfaction. Nevertheless, when viewed as a single concept, one possible explanation for the positive relationship is that the availability of training allowed the CNAs to perform at a higher level which in turn resulted in feelings of job satisfaction and commitment to the NH. A second possible explanation is that those CNAs who felt positively about their job were more likely to feel positively about the services provided by the $\mathrm{NH}$, including training. In this case, their perception of available training would be prejudiced by their attitude toward the $\mathrm{NH}$ as a whole.

Self-esteem and the perception of being treated fairly were other CNA attitudes considered. Their relationships to perceived training were relatively small (.04 and .06 respectively). Here again, it is reasonable to suspect that most of the training available to CNAs, and what CNAs expected, dealt with how to do the work. Much less focused on the CNA's perceptions of themselves (e.g., "I feel I am a valuable person," "I feel I do NOT have much to be proud of") or on the relationship between themselves and the NH management (e.g., "CNAs who do a good job are recognized," "Doing a good job at work is rewarded with higher pay"). Consequently, the CNA's did not likely expect training to include a focus on self esteem or on employee-employer relations when asked if training was always available when needed.

Among the variables reflecting burnout, "exhaustion" had the strongest relationship $($ ANCOVA eta square $=.07)$. Exhaustion, as measured in the Likert statements, reflects the CNAs feelings of being "emotionally drained", "burned out", "used up", and "strained". If the CNA perceived training to always be available when needed, then these feelings were less. This suggests that availability of training assists a CNA in overcoming these feelings of burnout and 
this is a reasonable conclusion, particularly if some of the training available addressed issues surrounding burnout. Burnout has been a concern of $\mathrm{NH}$ managers as studies have begun to show the negative effects it has on turnover and job performance. Consequently, it is not unreasonable to suspect that NH managers have begun including issues surrounding burnout into the training available to CNAs.

The two other measures of burnout, depersonalization and efficacy, showed less relationship to perceived training availability (ANCOVA, eta squared $=.04$ for each). Depersonalization refers to how the CNA relates to the residents including: not caring what happens to some residents and treating some residents as impersonal objects. The findings suggest that availability of training has little impact on these perceptions though what relationship does exist is in the direction expected, i.e., a perception of available training is negatively related to depersonalization. This suggests that either available training does not routinely attempt to address issues surrounding feelings of depersonalization or that the available training has been unsuccessful. The feeling of efficacy was measured from Likert statements that included phrases such as "I feel I am positively influencing others" and "I have all the skills and knowledge I need to do a good job and I use them”. Here again, the relationship to perceived availability of training was small. That is, feelings of efficacy differed very little between those who perceived training to be available when needed and those who did not. This finding is somewhat puzzling given that CNA training is typically designed to improve CNA skills and knowledge. However, several studies have found that training received can sometimes be difficult to transfer into skills and knowledge actually used on the job (Broad, 1997; Aylward, et al., 2003). To the extent that CNA training was not easily transferred into skills and 
knowledge that could be actually used to improve resident care, the data are likely to show little relationship between training and self-reported efficacy.

The last set of dependent variables to be considered is related to CNA turnover. Those CNAs who perceived training to be always available when needed were less likely to intend to quit their job $(\mathrm{ANCOVA}$ eta squared $=.06)$. Because it is unlikely that the CNA training directly focused on turnover, having available training when needed is likely to have instilled other feelings and perceptions that resulted in less desire to leave the NH. For example, those CNAs who perceived training to be always available may have interpreted this to mean that $\mathrm{NH}$ management had confidence in their capacity to learn, to become highly knowledgeable about their work, and to perform their work at the highest levels. Always having training available may suggest to the CNA that NH manangement is attempting to support them so that they can do a good job. On the other hand, where training is perceived to be not always available, the CNA may feel that the NH management has little desire or interest in investing in the CNA.

Consequently, the CNA may have an intention to quit and take a job at a NH where more support may be perceived to be forthcoming.

Interestingly, the variable "length of employment" was not found to be related to availability of training. One possibility for this finding is related to this variables skewness which can affect subsequent statistical analyses. While a log 10 transformation was performed which appeared to correct for the non-normal nature of this variable, a non-significant relationship still exists. Examination of the means prior to the transformation also showed a nonsignificant effect. However, the means are in the direction expected. CNAs who disagreed or strongly disagreed with the statement that training was always available had an average length of 
employment of 38 months. Those who agreed or strongly agreed with the statement had an average length of employment of 45 months.

\section{Conclusion}

A variety of studies have found a relationship between training and CNA performance (e.g., Majumdar, et al., 2004; Burgio, et al., 2000). Our analyses support these previous studies. Those CNAs who perceived training to be always available rated information exchange much higher than those who did not perceive training to be always available. Likewise, those who perceived training to be always available rated the procedures used at the $\mathrm{NH}$ higher and care of residents higher.

When considering CNA turnover, one of the measures supported previous studies (e.g., Morgan and Konrad, 2008; Nakhnikian, Wilner, and Hurd, 2002) by showing a significant relationship while a second measure did not. More specifically, those who perceived training to be always available reported less intention to quit than those who disagreed/strongly disagreed that training was always available. Length of employment was not found to be significant with the result possibly due to the non-normal nature of the variable (unaltered means were in the direction expected but not significant).

The data support previous studies reporting that training is positively related to CNA attitudes (e.g., Ejaz, et al., 2008; Owens, 2006). Those who perceived training always available when needed scored higher on job satisfaction/commitment, feelings of being treated fairly by management, and self-esteem than did those who did not perceive training always available. Similar support for previous research (e.g., Coogle, et al., 2007; Hatinen, et al., 2004) was found 
with regard to burnout. Those who perceived training to be always available scored lower on exhaustion, depersonalization, and efficacy.

An examination of empowerment showed mixed results. Those who perceived training always available were more likely to participate in decision-making but were not any more likely to have direct decision-making authority than those who did not perceive training to be always available. While this latter finding is puzzling, one possible explanation is that those CNAs who had direct decision-making authority perceived a greater need for training than did those who only participated in decision-making. Consequently, with greater training needs, some of these CNAs may have felt that training was not always available when needed.

\section{Implications and Recommendations}

The findings provide several implications and subsequent recommendations. CNA attitudes about their jobs and about themselves were found to be associated with their perceived availability of training. This included satisfaction/commitment, exhaustion from the work, feelings of empowerment, and intentions to quit. To the extent that the findings can be generalized, they suggest that $\mathrm{NH}$ administrators and Directors of Nursing can have desirable impacts on these through training. More specifically, the result can be happier, less "burnout" and more empowered CNAs and this, in turn, is likely to result in better care provided to residents. Further, the data analyses suggest that there may not have been training focused on several additional CNA attitudes including self-esteem and feelings of depersonalization ("I don't really care what happens to some residents"). Additional training in these areas may also provide opportunities for improved resident care. 
Not surprising, perceived availability of training was also found to be related to CNA performance including the procedures used to care for residents and the updating of resident information over time. While this confirms that training is important to resident care, further data analyses suggested that there may have also been instances when the training provided did not enhance resident care. For example, when examining self-efficacy, those perceiving more training were no more likely than those perceiving less training to agree that "I have the skills and knowledge I need to do a good job and I use them.” This suggests that simply providing training to enhance skills and knowledge is not enough. There is also a need to provide training in how to transfer these skills and knowledge to the actual care of residents. 


\section{References}

Aylward S, Stolee P., Keat N., and Johncox V. 2003. Effectiveness of continuing education in long-term care. The Gerontologist, 43: 259-271. [PMid:12677083].

Banaszak-Holl J., and Hines MA. 1996. Factors associated with nursing home staff turnover. The Gerontologist, 36: 512-517. [PMid:8771979].

Beck C, Ortigara A, Mercer S, and Shue V. 1999. Enabling and empowering Certified Nursing Assistants for quality Dementia care. International Journal of Geriatric Psychiatry 14:197-212. [doi:10.1002/(SICI)1099-1166(199903)14:3<197::AID-GPS972>3.0.CO;2-Q]

Braun KL., Suzuki KM., Cusick, C E., and Howard-Carhart K. 1997.Developing and testing training materials on elder abuse and neglect for nurse aides. Journal of Elder Abuse and Neglect, 9:1-15. [doi:10.1300/J084v09n01_01]

Broad ML. 1997. Overview of transfer of training. Performance Improvement Quarterly, 10: $7-21$.

Burgio LD, Allen-Burge R, Roth, DL, Bourgeois MS, Dijkstra K, Gerstle J, Jackson D, and Bankester L. 2000. Come talk with me. The Gerontologist 41: 449-460.

Burgio LD, and Burgio KL. 1990. Institutional staff training and management: A review of the literature and a model for geriatric, long-term-care facilities. International Journal of Aging and Human development 30: 287-302. [PMid:2118881]

Chappell NL, and Novak M. 1992. The Role of Support in Allleviating Stress among Nursing Assistants. The Gerontologist, 32: 351-359. [PMid:1500000].

Coogle CL, Parham IA., Jablonski R, and Rachel JA. 2007. The value of geriatric care enhancement training for direct service workers. Gerontology and Geriatrics Education 28: 109131. [doi:10.1300/J021v28n02_08]. 
Cook JD, Hepworth SJ, Wall TD, and Warr PB. 1979. The experience of work. New York: Academic Press.

Ejaz FK, Noelker LS, Menne HL, and Bagakas J. 2008. The impact of stress and support on direct care workers' job satisfaction. The Gerontologist 48(Special Issue): 60-70. [PMid:18694987].

Fitzgarald C, Ecclestone N, Jones G, Orange JB., Stolee P, and Lazowski D. 2001. Restorative care education and training in long-term care institutions. Gerontology 47(Supplement 1): 584.

Grant LA, Kane RA., Potthoff SJ, and Ryden M. 1996. Staff training and turnover in Alzheimer special care units. Geriatric Nursing: 278-282.

[doi:10.1016/S0197-4572(96)80241-2].

Hackman, JR, and Oldham GR. 1980. Work Redesign. Reading, MA: Addison-Wesley Publishing.

Harris-Kojetin L, Lipson D, Fielding J, Keifer K, and Stone RI. 2004. Recent findings on frontline long-term care workers. Available:

http://aspe.hhs.gov/dalongtermcarep/reports/insight.pdf (Accessed Retrieved January 18, 2007).

Hatinen M, Kinnunen U, Pekkonen M, and Aro A. 2004. Burnout patterns in rehabilitation. Journal of Occupational Health Psychology 9: 220-237. [PMid:15279517].

Hoeffer B, Talerico KA, Rasin J, Mitchell CM, Stewart BJ, McKenzie D, Barrick AL, Rader J, and Sloane PD. 2006. Assisting cognitively impaired nursing home residents with bathing. The Gerontologist 46: 524-532. [PMid:16921006].

Johncox V. 2000. Evaluability assessment of staff training in special care units for persons with dementia. Canadian Journal of Program Evaluation, 150 (special issue): 53-66. 
Legg TJ. 2007. Staff development. Nursing Home Magazine: 28-35.

Leiter M, and Schaufeli W. 1996. Consistency of the burnout construct across occupations. Anxiety, Stress, and Coping 98:229-243. [doi:10.1080/10615809608249404]

Maas M, Buckwalter KC, Swanson E, and Mobily PR. 1994. Training key to job satisfaction. Journal of Long-Term Care Administration 1: 23-26.

Majumdar B, Browne G, Roberts J. and Carpio B. 2004. Effects of Cultural sensitivity training on health care provider attitudes and patient outcomes. Journal of Nursing Scholarship 2:161-166. [doi:10.1111/j.1547-5069.2004.04029.x] [PMid:15227764]

Maslach C, Jackson SE, and Leiter MP. 1996. Maslach burnout inventory manual (third edition). Palo Alto, California: Consulting Psychologists Press, Inc.

McGee G, and Ford RC. 1987. Two (or more) dimensions of organizational commitment: Reexamination of the affective and continuance commitment scales. Journal of Applied Psychology, 72: 638-642. [doi:10.1037/0021-9010.72.4.638]

Menne H, Ejaz FK., Noelker LS, and Jones JA. 2007. Direct care workers' recommendations for training and continuing education. Gerontology and Geriatrics Education 28: 91-108. [doi:10.1300/J021v28n02_07]

Morgan JC, and Konrad TR. 2008. A mixed-method evaluation of a workforce development intervention for nursing assistants in nursing homes. The Gerontologist 48 (special issue): 71-79. [PMid:18694988]

Nakhnikian E, Wilner MA, and Hurd D. 2002. Nursing assistant training and education. Nursing Home Magazine: 44-47.

Owens PL. 2006. One more reason not to cut your training budget. Public Personnel Management 35:163-172. 
Quinn RP, and Staines GL. 1979. The 1977 quality of employment survey. University of Michigan, Ann Arbor, Michigan: Institute of Social Research.

Schur D, Noelker LS, Looman W, Whitlatch CJ, and Ejaz FK. 1998. Four steps to more committed nursing assistants. Balance 32: 29-32.

Spreitzer G. 1995. Psychological empowerment in the workplace. Academy of Management Journal 38: 1442-1465.[doi:10.2307/256865]

Stott AL, Brannon SD, Vasey J, Kansky KH, and Kemper P. 2007. Baseline management practices at providers in Better Jobs Better Care. Gerontology and Geriatrics Education 28: 1736. [doi:10.1300/J021v28n02_03]

Wunderlich GS, and Kohler PO. 2001. Improving the quality of long-term care. Washington, D.C.: National Academy Press.

Yeatts DE, and Cready MC. 2007. Consequences of empowered CNA teams in nursing home settings: A longitudinal assessment. The Gerontologist 47:323-339. [PMid:17565096]

Yeatts DE, and Hyten C. 1998. High-performing self-managed work teams: A comparison of theory to practice. Thousand Oaks, CA: SAGE, Inc. 
Table 1: Characteristics of CNA Survey Participants

\begin{tabular}{|c|c|c|c|c|}
\hline Characteristic & Mean & $\begin{array}{l}\text { Standard } \\
\text { Deviation }\end{array}$ & Percentage & Number of Cases \\
\hline Education, Highest Year & 11.8 & 2.0 & & 326 \\
\hline Age & 36.7 & 11.8 & & 329 \\
\hline \# Children at Home & 1.5 & 1.5 & & 339 \\
\hline \multicolumn{5}{|l|}{ Sex } \\
\hline Female & & & 87.5 & 314 \\
\hline Male & & & 12.5 & 45 \\
\hline \multicolumn{5}{|l|}{ Race } \\
\hline White & & & 42.3 & 152 \\
\hline Black & & & 41.8 & 150 \\
\hline Hispanic & & & 10.3 & 37 \\
\hline Other & & & 5.6 & 20 \\
\hline \multicolumn{5}{|l|}{ Marital Status } \\
\hline Married & & & 47.0 & 156 \\
\hline Single & & & 45.0 & 163 \\
\hline Single and living with $\mathrm{s}$ & omeone & & 8.0 & 28 \\
\hline \multicolumn{5}{|c|}{ Difficulty Paying Bills } \\
\hline Usually/Always & & & 42.1 & 147 \\
\hline Sometimes & & & 33.5 & 117 \\
\hline Rarely/never & & & 24.4 & 85 \\
\hline
\end{tabular}


Table 2: Effects of Perceived Availability of Training on CNA Performance, Turnover, Attitudes, Burnout, and Empowerment

(please see separate file-I could not figure out how to merge a landscape file with a normal file) 